\title{
High aspect ratio lithium niobate ridge waveguides fabricated by optical grade dicing
}

Nadège Courjal, Blandine Guichardaz, Gwenn Ulliac, Jean-Yves Rauch, Benattou Sadani, Hui-Hui Lu, and Maria-Pilar Bernal

Corresponding author : Nadège Courjal

Email: nadege.bodin@univ-fcomte.fr

Telephone number : 333-81-66-55-85

Postal address :

Département d'Optique, FEMTO-ST,

16 rte de Gray,

25030 Besançon

FRANCE 


\title{
High aspect ratio lithium niobate ridge waveguides fabricated by optical grade dicing
}

\author{
Nadège Courjal, Blandine Guichardaz, Gwenn Ulliac, Jean-Yves Rauch, Benattou Sadani, Hui- \\ Hui Lu and Maria-Pilar Bernal
}

FEMTO-ST Institute, Université de Franche-Comté, Besançon 25030, FRANCE

\begin{abstract}
We report the development of a quick process for fabricating lithium niobate ridge waveguides with smooth walls, aspect ratios larger than 500 and side wall verticality of $88^{\circ}$. The method is based on optical grade dicing, and allows the fabrication of ridges with a top width of $1 \mu \mathrm{m}$ and a depth of more than $500 \mu \mathrm{m}$. Smart-cut ridge waveguides and strongly confined proton exchanged ridge waveguides are demonstrated. We show that the method enables the fabrication of ridge waveguides with propagation losses as low as $0.5 \mathrm{~dB} / \mathrm{cm}$. A new fabrication process is thus proposed for the fabrication of optical components with enhanced acousto-optic, electro-optic or nonlinear interactions. The high aspect ratios open opportunities toward the development of 3D photonic components in thin films of $\mathrm{LiNbO}_{3}$, and toward hybrid integration of $\mathrm{LiNbO}_{3}$ components.
\end{abstract}

\subsection{Introduction}

Ridges waveguides in lithium niobate subtrates have been attracted much attention over the past thirty years, due to their potentialities of enhancing electro-optical, nonlinear or acousto-optical interactions. In 1974 Kaminow et al. reported the fabrication of ridges in the view of increasing the electro-optic interaction in comparison with planar waveguides [1]. Since then, Ti-indiffusion or proton exchange (PE) based techniques have become routine procedures for the fabrication of low loss $\mathrm{LiNbO}_{3}$ optical waveguides. Ti-indiffused waveguides or their PE counterparts exhibit low refractive index contrasts and consequently a weak confinement of light. If etched on their sides, standard waveguides can benefit from a higher lateral index contrast, which enables an increased confinement of light and a higher overlap coefficient between the guided optical wave and the modulating microwave signal in electro-optic (EO) devices. Consequently, ridges appear as an efficient tool for reducing the halfwave voltage of EO modulators. By introducing air between two adjacent optical channels, they also help preventing light coupling, and contribute to the improvement of extinction ratios [2]. In addition, ridges help broadening the EO bandwidth by providing a low dielectric material around the electrodes, which reduces the velocity mismatch between the light wave and the microwave signal [3]. The studies dedicated to the fabrication of ridges have known a regain of interest very recently, due to the development of new microstructured or nanostructured $\mathrm{LiNbO}_{3}$ photonic components [4-6] for which a strong light confinement is mandatory. The high number of papers that still deal with the subject shows that there is a current need for a method enabling the fabrication of ridges with low propagation losses, smooth and vertical walls with a process that is not too much time consuming and expensive.

Ultrafast laser machining, which is amenable to directly pattern any material with trenches as deep as several hundreds of micrometers could appear as a potential candidate for meeting the requirement of 
a quick process. A recent paper has shown the feasibility of the technique for the fabrication of polaritonic structures in $\mathrm{LiNbO}_{3}$ substrates, with aspect ratios (depth/width) of 10 or more [7]. However, a roughness below 100nm seems difficult to be reached by laser machining, due to the significant chemical and structural alterations induced by the laser spot [7]. Other approaches based on direct plasma etching techniques have been tested. Their high chemical reactivity with the material make fluor gases the best candidates for plasma etching $\mathrm{LiNbO}_{3}$ substrates, but on the downside they lead to the formation and redeposition of LiF composites [8]. Hence, the etched surfaces exhibit a roughness that is not compatible with low optical losses. Improving the smoothness of the walls requires a preliminarily step that prepares the material. As an example, proton exchange replaces $\mathrm{Li}$ ions with protons [9-11] and helps preventing $\mathrm{LiF}$ redeposition: the resulting structures can exhibit a roughness lower than $20 \mathrm{~nm}$ and aspect ratios of 10 [10]. But the associated side wall verticality does not exceed $82^{\circ}$, and depths larger than $10 \mu \mathrm{m}$ cannot be attained without a severe deterioration of the roughness. Wet etching techniques associated with ion implantation, proton exchange or domain inversion, have also been widely studied [12-14]. If the wet etching process is prepared with an annealing step, and followed by a subsequent step of Ti-indiffusion, the method shows to be very efficient for the fabrication of ultra-smooth ridges with a roughness of $20 \mathrm{~nm}$ and propagation losses as low as $0.05 \mathrm{~dB} / \mathrm{cm}[15,16]$. But such processes can only be applied on the $-\mathrm{z}$ face of $\mathrm{LiNbO}_{3}$ substrates. There is however a high interest in achieving similar performances on X-cut substrates, which are widely used for the fabrication of electro-optic components. It should also be outlined that except laser machining, all the techniques reported above typically require more than ten hours of total processing, and preliminary lithographic steps.

In ref. [17], the use of a dicing saw is mentioned for the development of periodically poled $\mathrm{Zn}: \mathrm{LiNbO}_{3}$ ridges waveguides. Here we provide a detailed process for obtaining smooth ridges waveguides with aspect ratios that can be larger than 500 , propagation losses as low as $0.5 \pm 0.48 \mathrm{~dB} / \mathrm{cm}$ and with a side wall verticality of $88^{\circ}$. The method applies indifferently to Z-cut or X-cut substrates, for any direction of propagation, and takes less than thirty minutes of process for the fabrication of one ridge. It presents a particular interest for the development of smart waveguide prototypes, when only one small area of the wafer needs to be processed. It also offers new opportunities of developing thin films of $\mathrm{LiNbO}_{3}$, and eases the way toward hybrid integration of $\mathrm{LiNbO}_{3}$ photonic components.

\section{Description of the process and preliminary results}

The process described hereunder can be used indifferently with $\mathrm{X}$-cut, Z-cut $\mathrm{LiNbO}_{3}$ substrates, and slice-cut samples. The thickness of the $\mathrm{LiNbO}_{3}$ layers may vary from $1 \mu \mathrm{m}$ (namely layers made by smart cut) to $1 \mathrm{~mm}$ (Crystal Technology congruent $\mathrm{LiNbO}_{3}$ wafers). A first step consists in fabricating a planar waveguide either by Ti-indiffusion, Annealed Proton Exchange or via thin film forming technologies such as Smart Cut, which is used to produce silicon on insulator (SOI) wafers $[18,19]$. The purpose of fabricating a planar waveguide is to provide a vertical confinement of the light wave. The ridge structure is realized in a second step by "optical grade dicing" with a circular precision saw (DISCO DAD 321).

In view of performing the dicing step, the $\mathrm{LiNbO}_{3}$ wafer is firstly stuck onto a $90 \mu \mathrm{m}$ thick UV sensitive adhesive film surrounded by a frame. The frame is itself maintained by a vacuum substrate holder. The important criteria for obtaining a proper polishing of the substrate rely on the choice of the blade, and on its speed. In the present case, the blade has a diameter of $56 \mathrm{~mm}$ and a thickness of $200 \mu \mathrm{m}$. The speed of the blade is controlled in order to polish the substrate simultaneously with its dicing: the rotation speed and the moving speed of the dicing saw are respectively $10000 \mathrm{rpm}$ and $0.2 \mathrm{~mm} / \mathrm{s}$. The spindle of the saw is cooled with water in order to keep a constant temperature of $18^{\circ} \mathrm{C}$ 
during the process. The high flow of water is also used in the aim of mixing the $\mathrm{LiNbO}_{3}$ particles with diamond particles, similarly to what is done in polishing systems. Such a process results in grooves that are diced and polished at the same time. If the grooves are spaced from a few microns, they form ridge waveguides between them.

The first main advantage of the method is outlined in figure 1(a), where we can see that aspect ratios (width/depth) larger than 500 may be reached. More precisely, we show in the right of figure 1(a) ridges with a top width of $1 \mu \mathrm{m}$ and a depth of $526 \mu \mathrm{m}$. Even if this performance is not needed for the implementation of optical waveguides with low losses, it provides nevertheless an idea of the enormous capability of the method, and opens appealing alternatives towards the development of thin $\mathrm{LiNbO}_{3}$ layers. As an example, the thin films may be exploited for the implementation of tridimensional optical circuits by means of bright spatial solitons [20]: thanks to the high index contrast provided by the deep ridge, the photorefractive effect is expected to be enhanced and to lead to an increased confinement of self trapped waveguides. The deep grooves provided by optical grade dicing may also be very appealing for ensuring hybrid integration of $\mathrm{LiNbO}_{3}$ components, or for guiding fibres toward the optical waveguides.

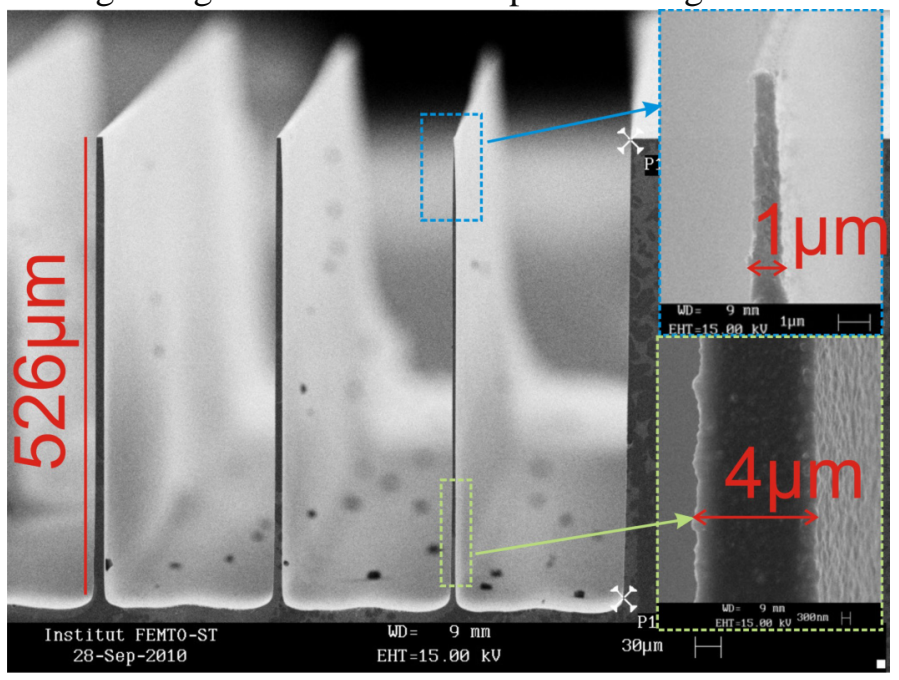

(a)

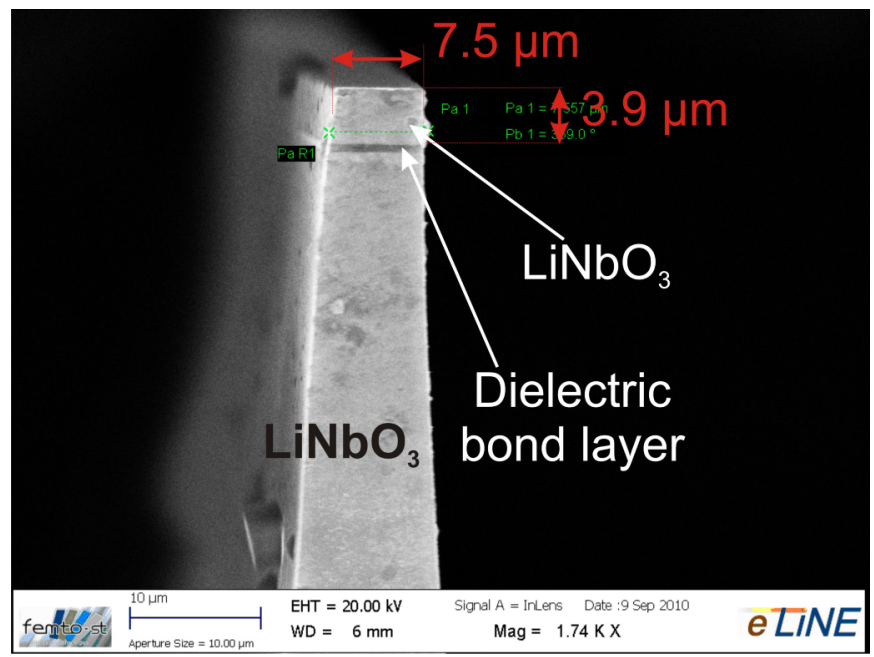

(c)

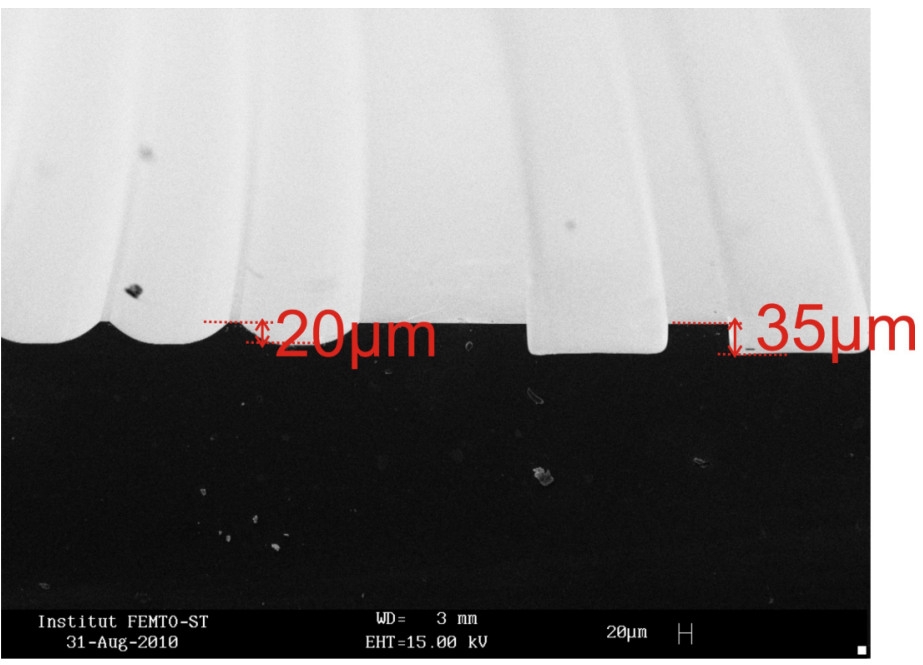

(b)

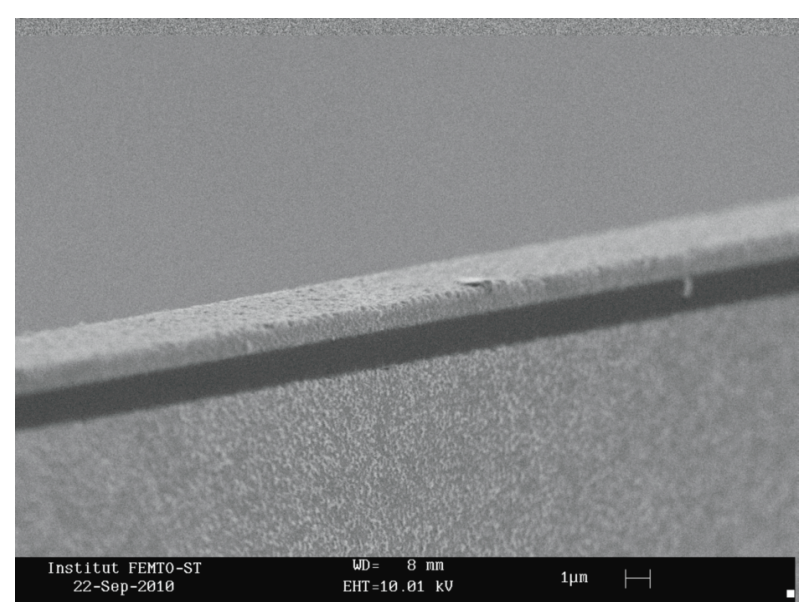

(d)

Figure 1. SEM views of the ridge structures. (a) Trenches with a depth of $526 \mu \mathrm{m}$. Rights: inserts show zoom views of the thinnest ridge of the serie (b) Different depths can be achieved on the same sample. (c) Smart-cut waveguide with a width of $7.5 \mu \mathrm{m}$ and a thickness of $4 \mu \mathrm{m}$. (d) Smart-cut waveguide with a $1 \mu \mathrm{m}$ thick layer of lithium niobate. 
In figure 1(b), we outline that a control of the ridge profiles can be achieved with the dicing saw: on the left of the image, the ridges exhibit non vertical walls and a depth of $20 \mu \mathrm{m}$ while ridges on the right exhibit a depth of $35 \mu \mathrm{m}$ and vertical walls. These two profiles were obtained by changing the shape and the depth of the blade.

In figures 1(c) and (d), we show how the optical grade dicing process can be applied to the development of $\mathrm{LiNbO}_{3}$ photonic wires integrated on thin films of Lithium niobate. Thin lithium niobate films may be formed using a process similar to the Smart Cut process used to fabricate silicon on insulator (SOI) wafers $[18,19]$. Alternatively, such thin films may be formed through bonding and mechanical or chemical thinning. The dielectric bond layer for the film also serves as an optical cladding for vertical confinement. As can be seen in the figures 1(c) and 1(d), end facets and sidewalls of the films were free of chipping and delamination, demonstrating that the optical grade dicing method is not limited to homogeneous congruent substrates.

One can notice that the samples are not cleaned after the process for avoiding any risk of breaking: consequently some dusts may be seen on the walls of the patterns. The optical characterization has been performed without cleaning the samples.

\section{Optical characterization}

Light confinement within the waveguides has been tested for various widths and depths of ridges implemented on Ti-indiffused or PE planar waveguides and smart-cut layers. The output of the waveguides is visualized at $1550 \mathrm{~nm}$ wavelength, with a 40x microscope objective that focuses the output light on a LHESA vidicon camera. The calibration of the digitalized pixels has been preliminarily performed by imaging a waveguide with a known intensity profile. Our purpose is to investigate the possibilities of confining light with minimal propagation losses.

The first series of ridges are planar waveguides made of $85 \mathrm{~nm}$ thick layers of titanium. These Ti-layers have been diffused into the substrate during 10 hours at $1020^{\circ} \mathrm{C}$. In these conditions, the Ti-indiffusion depth is of $5.3 \mu \mathrm{m}$ along the extraordinary axis, and of $4.2 \mu \mathrm{m}$ along the ordinary axis. These series have been fabricated for evaluating the influence of the ridge profile upon the TE and TM optical modes. Optical modes of X-cut Z-propagating ridges waveguides are reported in figure 2 . In this particular configuration, both TE and TM polarizations are submitted to the ordinary refractive index. In figure 2 (a), the SEM image shows an angle of $40^{\circ}$ between the surface of the substrate and the side-walls of the ridges. This sidewall-angle becomes $88^{\circ}$ for the $35 \mu \mathrm{m}$ deep ridge of figure 2 (d). The impact of the non verticality of the walls is seen in figures 2(b) and (e) and summarized in table 1: the full width at half maximum (FWHM) is reduced 1.9 times when the sidewall angle becomes $88^{\circ}$ (figure 2(b)) instead of $40^{\circ}$ (figure2(e)). In terms of lateral and vertical confinement, the behaviour is roughly the same for both TE and TM polarizations. 

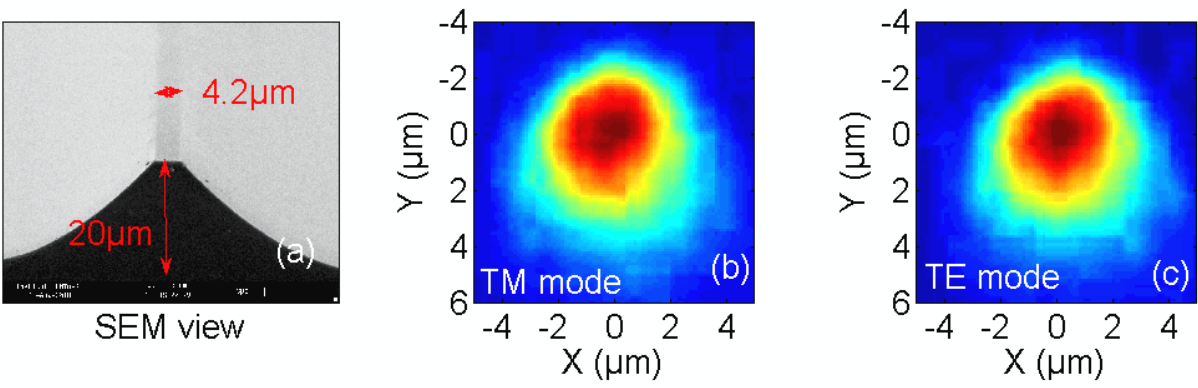

Optical

power

(a.u.)
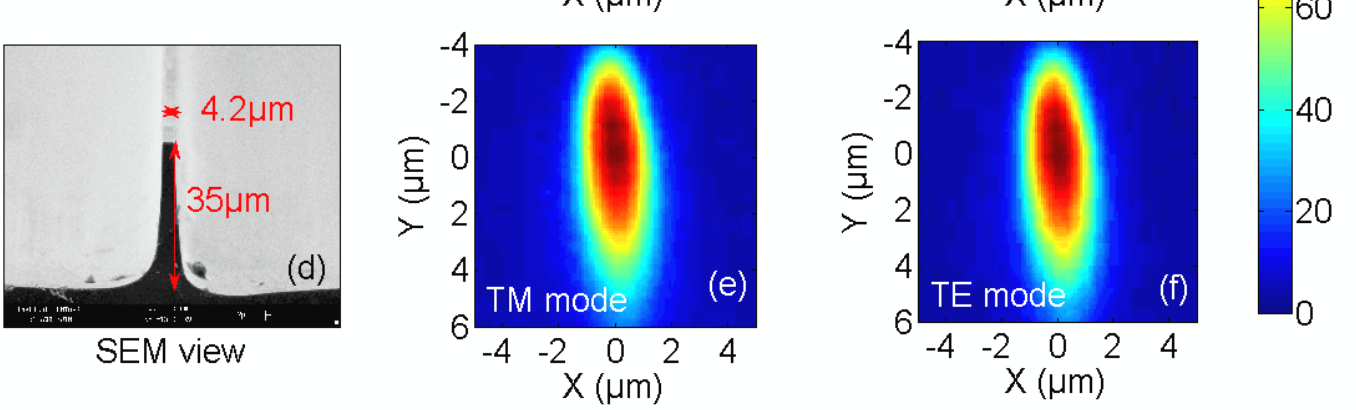

Figure 2. Study of ridge waveguides with a top width of $4.2 \mu \mathrm{m}$. (a), (b) and (c): Study of a non vertical ridge with a top width of $4.2 \mu \mathrm{m}$. (a) SEM view, (b) and (c) output TM and TE modes respectively. (d), (e) and (f): Study of a quasi-vertical ridge with a top width of $4.2 \mu \mathrm{m}$ and a depth of $35 \mu \mathrm{m}$. (d) : SEM view, (e) and (f) output TM and TE modes respectively.

We can also see in figure 2 that the lateral confinement is obtained at the expense of the vertical confinement. In order to provide a better vertical confinement, we have developed a second series of ridges waveguides with a stronger refractive index contrast. This is achieved by immersing the Tiindiffused samples into a bath of melted benzoic acid at $200^{\circ} \mathrm{C}$ : in these conditions, the $\mathrm{Li}^{+}$ions located at the surface of the substrate are replaced with $\mathrm{H}^{+}$ions. This proton exchange process induces a variation of the extraordinary refractive index of 0.13 , on a depth that depends on the temperature and time of immersion [21]. Several immersion times have been tested by steps of 3 hours up to a maximum of 15 hours of immersion time. These tests have shown us that minimal immersion duration of 12 hours is needed to obtain single mode propagation within a ridge with a top width of $3.5 \mu \mathrm{m}$. The resulting thickness of the exchanged layer is estimated to be $2.7 \mu \mathrm{m}$. The distribution of output intensity resulting from 6 hours and 12 hour of proton exchange at $200^{\circ} \mathrm{C}$ are exposed in figure 3(a) and (b) respectively for a $3.5 \mu \mathrm{m}$ large and $50 \mu \mathrm{m}$ deep ridge waveguide. In the case seen in figure 3(a), the exchanged layer is not thick enough: the light is guided within the rib delimited by the walls of the ridge rather than within the top exchanged layer. On the other hand, a proton exchange step of 12 hours allows the propagation of a well confined single mode. The TE mode shows a lateral FWHM of $1.6 \mu \mathrm{m} \pm 0.4 \mu \mathrm{m}$, and a vertical FWHM of $2.2 \mu \mathrm{m} \pm 0.5 \mu \mathrm{m}$. The TM mode is not guided, due to the anisotropic behaviour of the proton exchange process. In figure 3(c), we show the output of a 12 hours exchanged ridge waveguide with a width of $6 \mu \mathrm{m}$ and a depth of $526 \mu \mathrm{m}$. This image confirms the possibility of guiding ligth through extremely deep ridges. It can be noticed that beyond a width of $5.5 \mu \mathrm{m}$, the 12 hours exchanged ridges waveguides become multimode. 


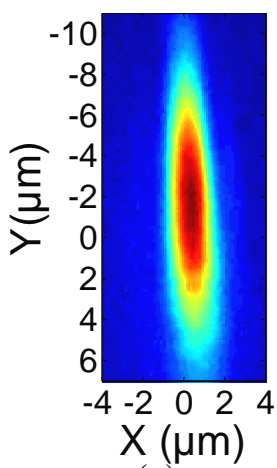

(a)

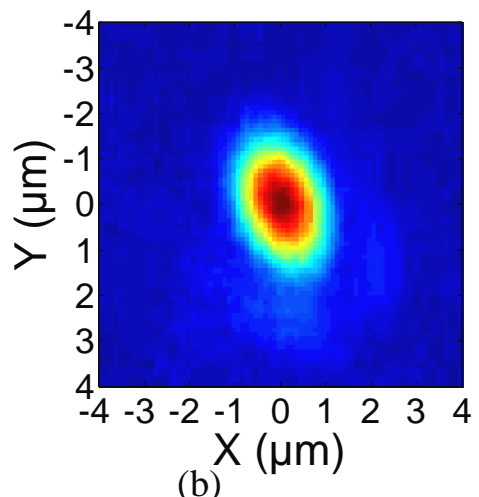

(b)

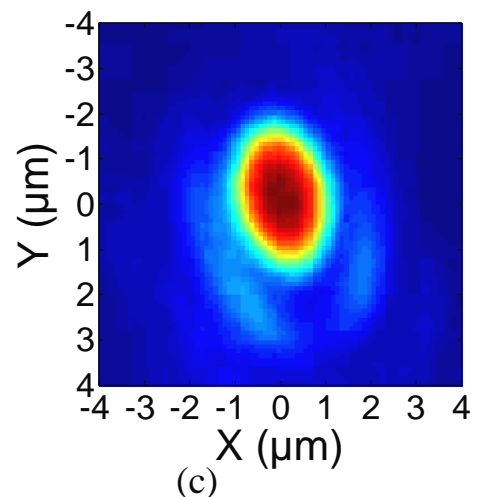

(c)

Figure 3. Output modes of proton exchanged Ti-indiffused ridges waveguides visualized with a 40x objective focusing on a LHESA Vidicon camera. (a) Visualisation of the light confined between the walls of a $35 \mu \mathrm{m}$ deep, $3.5 \mu \mathrm{m}$ large ridge waveguide for an immersion time of 6 hours at $200^{\circ} \mathrm{C}$ in melted benzoic acid. (b) Output of a $35 \mu \mathrm{m}$ deep $3.5 \mu \mathrm{m}$ large ridge waveguide for an immersion time of 12 hours. (c) Output of a 526 $\mu \mathrm{m}$ deep $6 \mu \mathrm{m}$ large ridge waveguide for an immersion time of 12 hours.

We have tested the influence of a subsequent annealing upon the optical mode in order to reduce the propagation losses inherent to PE waveguides. The resulting optical mode is non symmetric, and seems brighter in the region near the walls of the ridge than in its centre region. We attribute this effect to a non homogeneous diffusion of the protons, due to the walls of the ridge. This effect can be overcome by realizing the annealing step before dicing the samples: we are currently working on annealed proton exchanges planar waveguides in order to determine the optimal conditions for combining low propagation losses, high electro-optic interaction and optimal confinement of the light.

Another way of vertically confining light consists in exploiting thin $\mathrm{LiNbO}_{3}$ layers fabricated by wafer bonding and thin film forming technology such as Smart Cut. Dielectric bond layers used in such methods have index values comparable to glass, which produces a high degree of vertical confinement. The output of a $7 \mu \mathrm{m}$ large, $35 \mu \mathrm{m}$ deep ridge waveguide made of a $4 \mu \mathrm{m}$ thick layer of $\mathrm{X}$-cut lithium niobate is exposed in figure 4, showing a lateral FWHM of $1.3 \pm 0.3 \mu \mathrm{m}$, and a vertical FWHM of $1.6 \pm 0.4 \mu \mathrm{m}$.

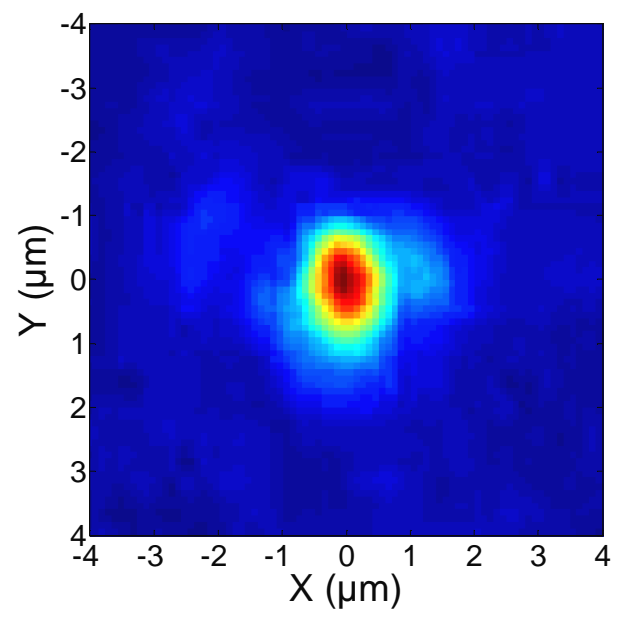

Figure 4. Output mode of a ridge waveguide with a width of $7 \mu \mathrm{m}$ made of a $4 \mu \mathrm{m}$ thick layer of lithium niobate.

The propagation losses are measured by exploiting the Fabry-Perot effect between the entrance and the output of the $7.45 \mathrm{~mm}$ long ridges fabricated on planar Ti-indiffused waveguides. Measurements are performed by scanning the transmitted optical intensity wavelength by wavelength, with a resolution of $0.01 \mathrm{~nm}$ from $1550 \mathrm{~nm}$ to $1554 \mathrm{~nm}$. The propagation losses $\alpha$ are extracted from the transmitted intensity maxima and minima according to the expression: 


$$
\left.\alpha=\frac{1}{L} \log (R)-\log (\tilde{R})\right)
$$

where $\alpha$ is expressed in $\mathrm{dB} / \mathrm{cm}, R$ is the reflectivity, $L=7.45 \mathrm{~mm}$ is the length of the waveguides, and $\widetilde{R}$ can be described as the contrast of the amplitude of the electric field :

$$
\tilde{R}=\frac{\sqrt{I_{\max }}-\sqrt{I_{\min }}}{\sqrt{I_{\max }}+\sqrt{I_{\min }}}
$$

$I_{\max }$ and $I_{\min }$ are respectively the maximum and the minimum of the transmitted intensity. In figure 4, we have provided an example of transmitted intensity. The reflectivity $\mathrm{R}$ is estimated from the group index $n_{g}$ of the ridge waveguide:

$$
R=\frac{\left(n_{g}-1\right)^{2}}{\left(n_{g}+1\right)^{2}}
$$

The group index is itself estimated from the free spectral range (FSR) of the transmission spectrum, as reported in reference [22]. The lowest propagation losses that have been measured are reported in figure 4 . They result from a waveguide with a top width of $6 \mu \mathrm{m}$ and a depth of $35 \mu \mathrm{m}$. If we follow equation (1) in its most advantageous way, we can claim propagation losses as low as $0.02 \mathrm{~dB} / \mathrm{cm}$, which is comparable to what is obtained through optimized Ti-indiffused waveguides. However, the indirect estimation of the propagation losses leads to considerable uncertainty of the measurement. In the view of evaluating more precisely the propagation losses, we have measured the transmitted intensity independently ten times, which has led us to an average estimation of the propagation losses, and to an estimation of the measurements error bar: $\alpha=0.50 \pm 0.48 \mathrm{~dB} / \mathrm{cm}$.

The propagation losses and the group index have been estimated for different widths of the $35 \mu \mathrm{m}$ deep ridge waveguides. The results are presented in figure 6: they show that contrary to what happens in non vertical ridges $[9,15]$, the propagation losses and the group index are pretty much the same for both polarizations. We can also observe that the losses tend to increase when the width of the ridge is reduced, which is not surprising since thin waveguides are more sensitive to imperfections of the walls or to the remaining dusts. However, the propagation losses remain relatively low even for thin ridges: they are typically of $2.5 \pm 2.4 \mathrm{~dB} / \mathrm{cm}$ for a ridge with a top width of $3.5 \mu \mathrm{m}$.

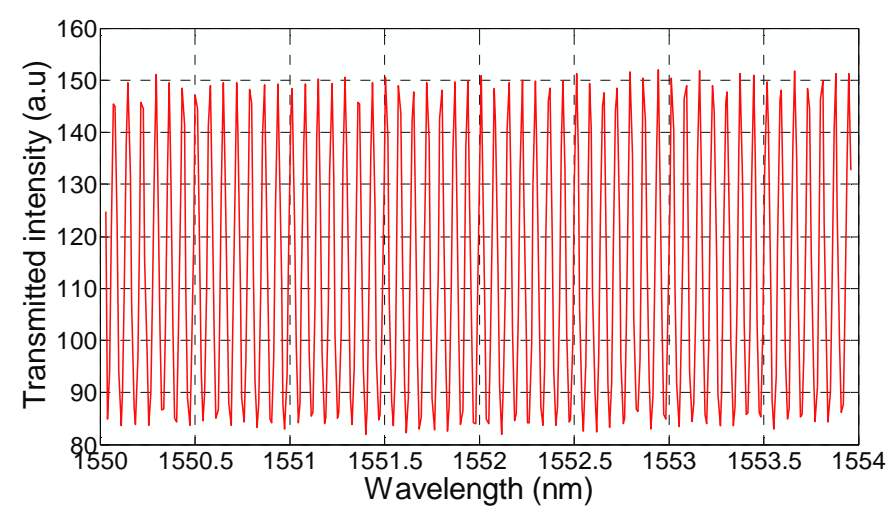

Figure 5. Transmitted intensity measured through a ridge waveguide with a top width of $6 \mu \mathrm{m}$ and a depth of $35 \mu \mathrm{m}$. The measurements were performed for a TE polarized mode propagating in the $\mathrm{Z}$ direction of a X-cut substrate submitted to Ti-indiffusion before the dicing step. 

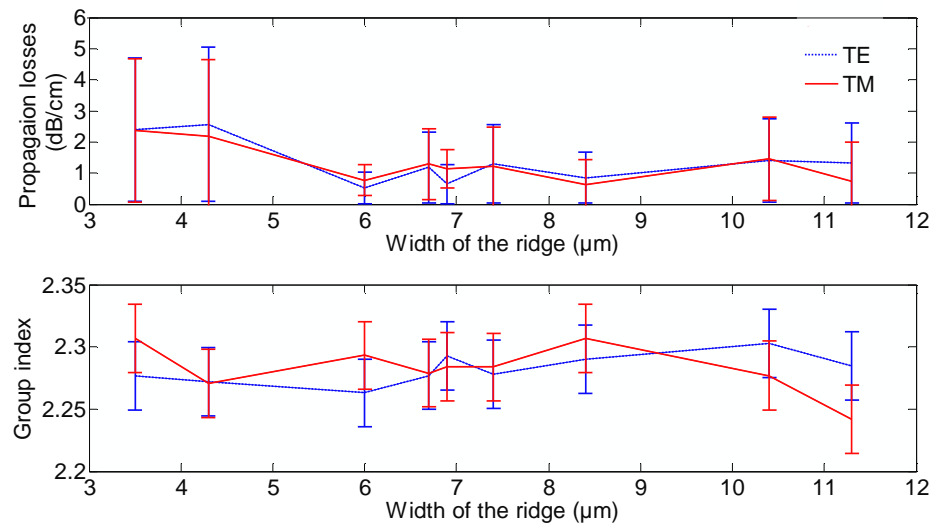

Figure 6. Influence of the width of the ridge upon the propagation losses and the group index for TE (dotted blue line) and TM (solid red line) polarisations. The depth of the ridge is of $35 \mu \mathrm{m}$, and the light propagates along the $\mathrm{Z}$-axis of the $\mathrm{X}$-cut substrate. The ridges are implemented on Ti-indiffused planar waveguides.

Table 1. Summary of the experimental results

\begin{tabular}{|c|c|c|c|c|c|c|c|}
\hline $\begin{array}{l}\text { Planar } \\
\text { waveguide }\end{array}$ & $\begin{array}{l}\text { Direction of } \\
\text { propagation }\end{array}$ & $\begin{array}{l}\text { Top } \\
\text { width }\end{array}$ & $\begin{array}{l}\text { Side-wall } \\
\text { verticality }\end{array}$ & Polarization & $\begin{array}{l}\text { Lateral } \\
\text { FWHM }\end{array}$ & $\begin{array}{l}\text { Vertical } \\
\text { FWHM }\end{array}$ & $\begin{array}{c}\text { Propagation } \\
\text { losses }\end{array}$ \\
\hline \multirow{8}{*}{$\begin{array}{c}\text { Ti- } \\
\text { indiffused }\end{array}$} & $Z$ & $4.2 \mu \mathrm{m}$ & $40^{\circ}$ & $\mathrm{TE}$ & $4.8 \mu \mathrm{m}$ & $4.8 \mu \mathrm{m}$ & $1.1 \mathrm{~dB} / \mathrm{cm}$ \\
\hline & & & & TM & $4.7 \mu \mathrm{m}$ & $5 \mu \mathrm{m}$ & $2.2 \mathrm{~dB} / \mathrm{cm}$ \\
\hline & & $4.2 \mu \mathrm{m}$ & $88^{\circ}$ & TE & $2.3 \mu \mathrm{m}$ & $7 \mu \mathrm{m}$ & $2.5 \mathrm{~dB} / \mathrm{cm}$ \\
\hline & & & & TM & $2.3 \mu \mathrm{m}$ & $7 \mu \mathrm{m}$ & $2.2 \mathrm{~dB} / \mathrm{cm}$ \\
\hline & & $6 \mu \mathrm{m}$ & $88^{\circ}$ & TE & $3 \mu \mathrm{m}$ & $5.6 \mu \mathrm{m}$ & $0.5 \mathrm{~dB} / \mathrm{cm}$ \\
\hline & & & & TM & $2.8 \mu \mathrm{m}$ & $5.4 \mu \mathrm{m}$ & $0.8 \mathrm{~dB} / \mathrm{cm}$ \\
\hline & & $7.4 \mu \mathrm{m}$ & $88^{\circ}$ & TE & $3.5 \mu \mathrm{m}$ & $5.2 \mu \mathrm{m}$ & $0.9 \mathrm{~dB} / \mathrm{cm}$ \\
\hline & & & & TM & $3.4 \mu \mathrm{m}$ & $5.2 \mu \mathrm{m}$ & $0.6 \mathrm{~dB} / \mathrm{cm}$ \\
\hline Ti- & $Y$ & $3.5 \mu \mathrm{m}$ & $88^{\circ}$ & TE & $1.6 \mu \mathrm{m}$ & $2.2 \mu \mathrm{m}$ & $15 \mathrm{~dB} / \mathrm{cm}$ \\
\hline $\begin{array}{c}\text { indiffused } \\
+12 \mathrm{~h} P \mathrm{E}\end{array}$ & & & & Simulation & $2.3 \mu \mathrm{m}$ & $1.2 \mu \mathrm{m}$ & \\
\hline Smart-Cut & $\mathrm{Y}$ & $7 \mu \mathrm{m}$ & $88^{\circ}$ & TE & $1.3 \mu \mathrm{m}$ & $1.6 \mu \mathrm{m}$ & - \\
\hline
\end{tabular}

A summary of the experimental results is presented in table 1. The depth is not reported as a key parameter in the table: according to our observations, the influence of the depth becomes negligible if the ridges are deeper than $20 \mu \mathrm{m}$. For smaller depths, it is difficult to obtain vertical walls and the lateral confinement is weaker. A strong confinement of the optical mode can be achieved with the use of Smart Cut or proton exchange processes, but this strong confinement is associated with propagation 
losses higher than $10 \mathrm{~dB} / \mathrm{cm}$. Finally, a compromise between confinement and propagation losses consists in patterning a Ti-diffused planar waveguide, with a top width of $6 \mu \mathrm{m}$, and a depth higher than $20 \mu \mathrm{m}$ : in that configuration, propagation losses of $0.5 \mathrm{~dB} / \mathrm{cm}$ can be reached, with a lateral FWHM of $3 \mu \mathrm{m}$.

\section{Conclusion}

As a conclusion, optical grade dicing process shows to be an extremely efficient tool for quick fabrication of straight ridge waveguides with smooth walls and high aspect ratios. We have demonstrated that a proper choice of the speed of the blade (namely $10000 \mathrm{rpm}$ ) during the dicing step can lead to smooth ridges with aspect ratios larger than 500 and a side wall verticality of $88^{\circ} \mathrm{C}$. Propagation losses as low as $0.5 \pm 0.48 \mathrm{~dB} / \mathrm{cm}$ have been measured on X-cut Z-propagating $6 \mu \mathrm{m}$ wide Ti-indiffused ridges waveguides. Tests were performed for combining a vertical confinement of light with the lateral confinement provided by the ridge structures. Thus, proton exchanged ridge waveguides with vertical FWHM of $2.2 \mu \mathrm{m}$, and smart-cut waveguides with a vertical FWHM of 1.6 $\mu \mathrm{m}$ have been tested. An optimal structure has been put in evidence with Ti-diffused planar waveguide exhibiting a top width of $6 \mu \mathrm{m}$ and a depth higher than $20 \mu \mathrm{m}$ : in that configuration, propagation losses of $0.5 \mathrm{~dB} / \mathrm{cm}$ can be reached, with a lateral FWHM of $3 \mu \mathrm{m}$. Work is in progress for optimizing the conditions of propagation and for implementing photonic structures onto the ridges, especially for the development of photonic sensors relying on functionalized photonic crystal ( $\mathrm{PhC})$ cavities [23]: the ridge structure is indeed mandatory for achieving the coupling between the $\mathrm{PhC}$ cavity and the input light. The ridge waveguides also help enhancing electro-optical interactions: the way is thus open toward the development of compact and sensitive electric field sensors.

\section{Acknowledgements}

This work was supported by the "MUSARAIGNE" DGA REI project contract number 0734022 and by the DARPA Contract Number HR0011-10-C-0043.

\section{References}

[1] I.P. Kaminow, V. Ramaswamy, R.V. Schmidt and E.H. Turner, 1974, Appl. Phys. Lett., 24, 622

[2] H. Haga, M. Izutsu and T. Sueta, 1986, IEEE J. Quantum Electron., 22, 902

[3] K. Noguchi, O. Mitomi, H. Miyazawa, and S. Seki, 1995, J. of Ligthwave technol., 13, 1164

[4] A. Suzuki, T. Iwamoto, A. Enokihara, H. Murata, and Y. Okamura, 2008, Microelectronic Engineering, 85, 1417

[5] N. Courjal, M.-P. Bernal, G. Ulliac, J. Dahdah, S. Benchabane and J.-M. Merolla, 2009, J. of the European Optical Society, 4, 09018

[6] G. Si, E.J. Teo, A.A. Bettiol, J.H. Teng, and A.J. Danner, 2010, Journal of vacuum science and technology $\mathrm{B}, \mathbf{2 8}, 316$

[7] D.W. Ward, E.R. Statz and K.A. Nelson, 2007, Applied Physics A, Material Science and processing, $\mathbf{8 6}, 49$ 
[8] H. Nagata, N. Mitsugi, K. Shima, M. Tamai, and E.M. Haga, 1998, Journal of Crytal Growth, 187, 573

[9] H. Hu, A.P. Milenin, R.B. Wehrspohn, H. Hermann, W. Sohler, 2006 , J. Vac. Sci, A 24(A), 1012

[10] G. Ulliac, B. Guichardaz, J.-Y. Rauch, S. Queste, S. Benchabane, N. Courjal, 2011, Microelectronic Engineering, MEE-D-10-00788R1

[11] Z. Ren, P.J. Heard, J.M. Marshall, P.A. Thomas, and S. Yu, 2008, J. of Appl. Phys. 103, 034109

[12] Y. Tan, and F. Chen, 2010, Optics Express, 18, 11444

[13] F. Laurell, J. Webjörn, G. Arvidsson, S. Holmberg, 1992, J. Lightwave Technol., 10, 1606

[14] I.E. Barry, G.W . Ross, P.G.R. Smith, and R.W. Eason, 1999, Appl. Phys. Lett., 74, 1487

[15] V. Dobrusin, S.Rushin, and L. Shpisman, 2007, Optical Material, 29, 1630

[16] H. Hu, R. Ricken, W. Sohler, 2010, Applied Physics B, 98, 677-679

[17] T. Nishikawa, A. Ozawa, Y. Nishida, M. Asobe, F.-L. Hong, and T. Hänsch, 2009, Optics Express,17, 17792-17800

[18] G. K. Cellera, S. Cristoloveanu, 2003, “J. of Appl. Physics, 93, 4955-4978.

[19] G. Poberaj, M. Koechlin, F. Sulser, A. Guarino, J. Hajfler, P. Günter, 2009, Optical Materials, 31, 1054-1058

[20] J. Safioui, M. Chauvet, F. Devaux, V. Coda, F. Pettazzi, M. Alonzo, and E. Fazio, 2008, J. Opt. Soc. Am. B, 26, 487

[21] T. Maciak, M. Sokolowski, 1989, Optica Applicata, 19, 423-428

[22] H. Hu, R. Ricken, W. Sohler, 2010, Optics Express, 17, 24261

[23] J. Dahdah, N. Courjal, and F. I. Baida, 2010, JOSA B, 27, 305-310 
Table 1. Summary of the experimental results

\begin{tabular}{|c|c|c|c|c|c|c|c|}
\hline $\begin{array}{l}\text { P lana } \\
\text { waveguide }\end{array}$ & $\begin{array}{l}\text { Direction of } \\
\text { propagation }\end{array}$ & $\begin{array}{l}\text { Top } \\
\text { width }\end{array}$ & $\begin{array}{l}\text { Side-wall } \\
\text { verticality }\end{array}$ & Polarization & $\begin{array}{l}\text { Lateral } \\
\text { FWHM }\end{array}$ & $\begin{array}{l}\text { Vertical } \\
\text { FWHM }\end{array}$ & $\begin{array}{c}\text { Propagation } \\
\text { losses }\end{array}$ \\
\hline \multirow{8}{*}{$\begin{array}{c}\text { Ti- } \\
\text { indiffused }\end{array}$} & Z & $4.2 \mu \mathrm{m}$ & $40^{\circ}$ & TE & $4.8 \mu \mathrm{m}$ & $4.8 \mu \mathrm{m}$ & $1.1 \mathrm{~dB} / \mathrm{cm}$ \\
\hline & & & & TM & $4.7 \mu \mathrm{m}$ & $5 \mu \mathrm{m}$ & $2.2 \mathrm{~dB} / \mathrm{cm}$ \\
\hline & & $4.2 \mu \mathrm{m}$ & $88^{\circ}$ & TE & $2.3 \mu \mathrm{m}$ & $7 \mu \mathrm{m}$ & $2.5 \mathrm{~dB} / \mathrm{cm}$ \\
\hline & & & & TM & $2.3 \mu \mathrm{m}$ & $7 \mu \mathrm{m}$ & $2.2 \mathrm{~dB} / \mathrm{cm}$ \\
\hline & & $6 \mu \mathrm{m}$ & $88^{\circ}$ & TE & $3 \mu \mathrm{m}$ & $5.6 \mu \mathrm{m}$ & $0.5 \mathrm{~dB} / \mathrm{cm}$ \\
\hline & & & & TM & $2.8 \mu \mathrm{m}$ & $5.4 \mu \mathrm{m}$ & $0.8 \mathrm{~dB} / \mathrm{cm}$ \\
\hline & & $7.4 \mu \mathrm{m}$ & $88^{\circ}$ & TE & $3.5 \mu \mathrm{m}$ & $5.2 \mu \mathrm{m}$ & $0.9 \mathrm{~dB} / \mathrm{cm}$ \\
\hline & & & & TM & $3.4 \mu \mathrm{m}$ & $5.2 \mu \mathrm{m}$ & $0.6 \mathrm{~dB} / \mathrm{cm}$ \\
\hline Ti- & Y & $3.5 \mu \mathrm{m}$ & $88^{\circ}$ & TE & $1.6 \mu \mathrm{m}$ & $2.2 \mu \mathrm{m}$ & $15 \mathrm{~dB} / \mathrm{cm}$ \\
\hline $\begin{array}{l}\text { Indiffused } \\
+12 \mathrm{~h} \mathrm{PE}\end{array}$ & & & & Simulation & $2.3 \mu \mathrm{m}$ & $1.2 \mu \mathrm{m}$ & \\
\hline Smart-Cut & Y & $7 \mu \mathrm{m}$ & $88^{\circ}$ & TE & $1.3 \mu \mathrm{m}$ & $1.6 \mu \mathrm{m}$ & - \\
\hline
\end{tabular}

